\title{
Iatrogenic Preterm delivery in pregnant woman with critical COVID-19 pneumonia and vertical transmission: A case report
}

Marzieh Zamaniyan ${ }^{1}$, Aghdas Ebadi², Samaneh Aghajanpoor Mir², Zahra Rahmani², Mohammadreza Haghshenas ${ }^{2}$, and Setareh Azizi ${ }^{2}$

${ }^{1}$ Mazandaran University of Medical Sciences

${ }^{2}$ Affiliation not available

May 5, 2020

\section{Hosted file}

Main document.doc available at https://authorea.com/users/306173/articles/436988-iatrogenicpreterm-delivery-in-pregnant-woman-with-critical-covid-19-pneumonia-and-verticaltransmission-a-case-report

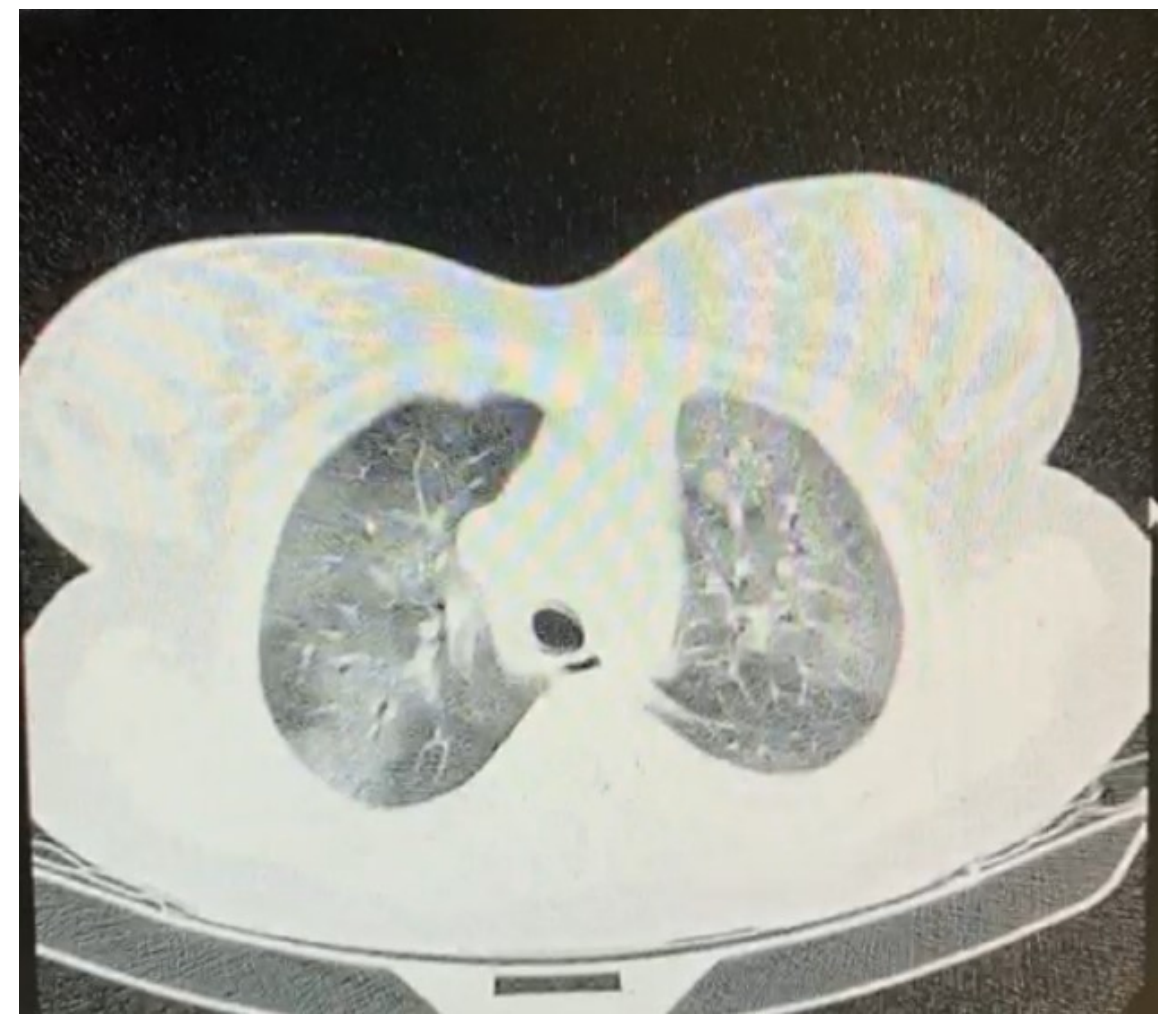

